\title{
Role of ROX index in the first assessment of COVID-19 patients in the emergency department
}

\author{
Alice Gianstefani ${ }^{1}\left[\right.$ - Gabriele Farina ${ }^{1}$. Veronica Salvatore ${ }^{1}$. Francesca Alvau ${ }^{1}$. Maria Laura Artesiani ${ }^{1}$. \\ Sara Bonfatti ${ }^{1}$. Francesca Campinoti ${ }^{1}$ - llaria Caramella ${ }^{1}$. Michele Ciordinik ${ }^{1}$. Andrea Lorusso ${ }^{1}$ - Sara Nanni ${ }^{1}$. \\ Daniela Nizza ${ }^{1} \cdot$ Stefano Nava $^{2} \cdot$ Fabrizio Giostra ${ }^{1}$
}

Received: 29 October 2020 / Accepted: 13 February 2021 / Published online: 1 March 2021

(c) Società Italiana di Medicina Interna (SIMI) 2021

\begin{abstract}
During the first outbreak of Coronavirus disease 2019 (COVID-19) Emergency Departments (EDs) were overcrowded. Hence, the need for a rapid and simple tool to support clinical decisions, such as the ROX index (Respiratory rate - OXygenation), defined as the ratio of peripheral oxygen saturation and fraction of inspired oxygen, to respiratory rate. The aim of the study was to evaluate the accuracy of the ROX index in predicting hospitalization and mortality in patients with a diagnosis of COVID-19 in the ED. The secondary outcomes were to assess the number of readmissions and the variations in the ROX index between the first and the second admission. This was an observational prospective monocentric study, carried out in the ED of Sant'Orsola-Malpighi Hospital in Bologna, Italy. Five hundred and fifty-four consecutive patients with COVID19 were enrolled and the ROX index was calculated. Patients were followed until hospital discharge or death. A ROX index value $<25.7$ was associated with hospitalization (area under the curve $[\mathrm{AUC}]=0.737,95 \%$ CI $0.696-0.779, p<0.001$ ). The ROX index $<22.3$ was statistically related to higher 30-day mortality (AUC $=0.764,95 \%$ CI $0.708-0.820, p<0.001$ ). Eight patients were discharged and returned to the ED within the subsequent 7 days, their mean ROX index was $30.3(6.2$; range $21.9-39.4)$ at the first assessment and $24.6(5.5 ; 14.5-29.5)$ at the second assessment, $(p=0.012)$. The ROX index, together with laboratory, imaging and clinical findings, correlated with the need for hospital admission, mechanical ventilation and mortality risk in COVID-19 patients.
\end{abstract}

Keywords ROX index $\cdot$ COVID-19 $\cdot$ Emergency department $\cdot$ Pandemic

\section{Introduction}

In late December 2019, clusters of severe atypical pneumonia were identified in Wuhan and in the Hubei Province of China. In Italy, since the first reports of symptomatic cases of Coronavirus disease 2019 (COVID-19) in late February 2020, as of April 30, 2020, 205,463 cases of Severe Acute Respiratory Syndrome 2 (SARS-CoV-2) infection have been reported. The curve of reported cases in the Italian epidemic showed a growing trend of new diagnoses until March 20th,

Alice Gianstefani

alice.gianstefani@aosp.bo.it

1 Emergency Department, University of Bologna Hospital of Bologna Sant'Orsola-Malpighi, via Albertoni 10, 40138 Bologna, Italy

2 Respiratory Disease Clinic, Sant'Orsola-Malpighi Hospital of the University of Bologna, Bologna, Italy followed by a constant decrease due to government restrictions [1]. According to the indication of the World Health Organization, diagnosis is based on the positivity of realtime reverse transcription-polymerase chain reaction (RTPCR) of oro- and nasopharyngeal swabs [2]; however, the sensitivity and specificity are poorly characterized, and the "window period" after acquisition in which testing is most likely to produce false-negative results is not well known [3]. As a consequence, in real clinical practice, specific radiological patterns on computed tomography (CT) and on lung ultrasound are also considered able to convey diagnosis and influence patient management [4].

The most frequent severe manifestation of infection appears to be interstitial pneumonia, characterized primarily by fever, cough, dyspnea, and bilateral infiltrates on chest imaging [5] with a prevalence of hypoxic respiratory failure of $19 \%$ [6, 7]. At admission to the Emergency Department (ED), these patients may show an atypical presentation of 
their symptoms, characterized by a mild increase in respiratory rate, in face of severe hypoxia probably due to their normal or only partially impaired respiratory mechanics. This particular presentation has been defined as $L$ (i.e. low elastance) versus the form closer to Acute Respiratory Distress Syndrome (ARDS), called $H$ (i.e. high elastance). The latter is characterized by a worse prognosis and, in the majority of cases, represented an evolution of presentation $L$ [8]. At the same time, a large cohort of patients exhibit only mild symptoms at first, such as myalgia, cough, fever and headache. Since the evolution of the disease is not yet well known with a possible sudden deterioration, one of the challenges which emergency physicians have to face is the early detection of patients who need to be hospitalized, and of those who can be directly and safely discharged. This is even more important when dealing with a rapidly spreading global pandemic, such as COVID-19, which has the potential of overwhelming hospital capacity [9]. Thus, the need for rapid and simple tools for emergency physicians to be able to support critical clinical decisions. For these reasons, the Authors tested the ROX index (Respiratory rate - OXygenation) which is defined as the ratio of peripheral oxygen saturation $\left(\mathrm{SpO}_{2}\right)$ and a fraction of inspired oxygen $\left(\mathrm{FiO}_{2}\right)$ to Respiratory Rate (RR). The ROX index was first described by Roca et al. in 2016 [10] in a bicentric prospective observational cohort study involving 157 patients with pneumonia/ARDS admitted to the intensive care unit (ICU) and treated with a high-flow nasal cannula (HFNC). It was shown that a ROX Index $<4.88$, measured $12 \mathrm{~h}$ after HFNC onset, was related to a higher risk of intubation (sensitivity $70.1 \%$, specificity $72.4 \%$ ). The same results were found in a subsequent multicentric prospective observational study, designed to validate the diagnostic accuracy of the index, which enrolled 191 patients with pneumonia admitted to the ICU and treated with HFNC [11]; a second external validation was carried out using the FLORALI cohort study [12]. In addition to its initial purpose the ROX Index was also applied as a predictor of successful HFNC weaning (cutoff value > 9.2) [13], and as an indicator to titrate $\mathrm{FiO}_{2}$ and set the optimal flow rates in patients with acute respiratory failure (ARF) treated with HFNC [14].

Based on these studies, the ROX index was identified as an easy-to-use instrument in COVID-19 patients who presented with hypoxemic ARF. To the best of the Authors' knowledge, the ROX index has not yet been applied in COVID-19 patients or in the initial patient assessment in the ED.

The primary aim of this prospective observational study was to evaluate the reliability and accuracy of the ROX index in predicting the need for hospitalization and the risk of mortality in patients with a suspected diagnosis of COVID-19 as they arrived in the ED. The secondary outcomes were to assess the number of readmissions in patients initially discharged and the variations in the ROX index in the time frame between the first and the second admission.

\section{Methods}

\section{Study design}

This was an observational prospective monocentric study, carried out in the ED of Sant'Orsola-Malpighi Hospital in Bologna, Italy, from 13 March to 3 April 2020. Five hundred and fifty-four consecutive patients with COVID-19 admitted to the ED were enrolled. Symptoms, such as fever, cough, dyspnea, sore throat, rhinorrhea, headache, fatigue, conjunctivitis, diarrhea, and smell or taste aberrancies, were considered likely to be related to SARS-CoV-2 infection This study was approved. by the local Ethics Committee (551/2020/ Oss/AOUBo).

\section{Participants}

The present analysis included patients with confirmed SARS-CoV-2 infection, determined by either:

- A positive result on RT-PCR of oro- and nasopharyngeal swabs at the initial test or at a test repeated during hospitalization, or

- Positive imaging findings on CT/lung ultrasound (interstitial pneumonia) despite a negative result on a nasopharyngeal swab test, without an alternative diagnosis at the time of discharge from the hospital.

These criteria were considered to be the best available in the period of enrollment based on the knowledge up tothat time.

\section{Data collection}

At the time of admission to the ED, demographic data, medical history and respiratory variables, such as $\mathrm{SpO}_{2}, \mathrm{FiO}_{2}$ and RR were collected. Based on these data, the ROX index was calculated using the formula: $\left(\mathrm{SpO}_{2} / \mathrm{FiO}_{2}\right) / \mathrm{RR}$. The National Early Warning Score 2 (NEWS2) was also calculated; it includes respiratory rate, hypercapnic respiratory failure occurrence, supplemental $\mathrm{O} 2$ need, temperature, systolic blood pressure, cardiac rate and level of consciousness [15]. In addition, all the patients underwent arterial blood gas (ABG) analysis, and at least one imaging test (chest $\mathrm{X}$-ray, lung ultrasound and/or high-resolution thoracic CT). Blood tests were carried out according to clinical evaluation. The patients were followed up until hospital discharge or death, and the medical records were extracted from the 
registry. The following data were obtained: hospitalization and 30-day mortality.

\section{Statistical analysis}

Demographic, clinical and laboratory characteristics of the cohort were expressed as means and standard deviation (SD), and as number and percentage as appropriate. The continuous variables were compared using the analysis of variance (ANOVA) $T$-test or the Mann-Whitney test, and the frequencies were compared using the chi-squared test. Areas under the curve (AUCs) and the 95\% confidence intervals (CIs) of the receiver operator characteristic (ROC) curves were computed to predict the need for hospitalization, presence of viral pneumonia and risk of 30-day mortality. The optimal ROX index cut-off was determined optimizing sensitivity and specificity, favoring sensitivity for the purposes of the study. A P-value less than 0.05 was considered significant. The statistical analyses were obtained using IBM SPSS Statistics software version 25.

\section{Patient and public involvement}

Due to the nature of the pandemic crisis, it was not possible to involve patients in the design, carrying out, reporting, or dissemination plans of the study.

\section{Results}

Of the 554 patients enrolled, the mean age was $61.5 \pm 19$ years, comparable to that described in the international literature [5]. In the present population, 53.4\% $(N=296)$ were male and $46.6 \%(N=258)$ were female which is consistent with Italian data [1]. The baseline characteristics are presented in Table 1.

The main comorbidities exhibited with a COVID-19 diagnosis were hypertension, diabetes mellitus, chronic obstructive pulmonary disease (COPD), chronic kidney disease, ischemic heart disease and asthma. The patients arrived at ED $6.3 \pm 5.2$ days after the onset of symptoms (Table 1). The majority of patients $(93.7 \%)$ were neurologically normal with a 15/15 Glasgow Coma Scale (GCS). The respiratory variables registered at admission were $\mathrm{SpO}_{2}(95.7 \% \pm 3.9)$, $\mathrm{RR}$ (20 breaths/min \pm 5.5$)$ and $\mathrm{FiO}_{2}\left(536\right.$ patients with $\mathrm{FiO}_{2}$ $21 \%$ and 18 with $\mathrm{FiO}_{2}>21 \%$, this last value based on that reported in the Ventimask kit used in the hospital ED).

The laboratory findings are listed in Table 1. In 4.9\% of the admissions, blood tests were not carried out due to mild symptoms. Lymphopenia was present in $44 \%$ of the population. Patients often presented with a normal white blood count $(7788 / \mathrm{mmc} \pm 5421)$, elevated C-reactive protein $(6.2 \mathrm{mg} / \mathrm{dl} \pm 7.2,0.02-40.7 \mathrm{mg} / \mathrm{dl})$ and lactate
Table 1 Baseline characteristics of the cohort $(n=554)$

\begin{tabular}{|c|c|}
\hline Age, years & $61.5 \pm 19$ \\
\hline \multicolumn{2}{|l|}{ Gender, $n(\%)$} \\
\hline Male & $296(53.4)$ \\
\hline Female & $258(46.6)$ \\
\hline \multicolumn{2}{|l|}{ Comorbidities, $n(\%)$} \\
\hline Hypertension & $204(36.3)$ \\
\hline Use of RAAS inhibitors & $52(9.4)$ \\
\hline Use of ARB inhibitors & $55(9.9)$ \\
\hline Diabetes mellitus & $62(11.2)$ \\
\hline COPD & $58(10.5)$ \\
\hline Asthma & $13(2.3)$ \\
\hline Other respiratory diseases & $22(4)$ \\
\hline Ischemic heart disease & $41(7.4)$ \\
\hline Active cancer & $33(6)$ \\
\hline Chronic kidney disease & $46(6.6)$ \\
\hline Previous TIA/stroke & $26(4.7)$ \\
\hline Liver disease & $22(4)$ \\
\hline Cognitive impairment & $72(13)$ \\
\hline Onset of symptoms, days & $6.5 \pm 5.2$ \\
\hline \multicolumn{2}{|l|}{ Clinical features at ED admission, $n(\%)$} \\
\hline Fever & $461(83.4)$ \\
\hline Dyspnea & $209(37.8)$ \\
\hline Cough & $315(57)$ \\
\hline Conjunctivitis & $8(1.4)$ \\
\hline Rhinorrhea & $21(3.8)$ \\
\hline Sore throat & $39(7.1)$ \\
\hline Headache & $45(8.1)$ \\
\hline Asthenia & $90(16.3)$ \\
\hline Myalgia/Arthralgia & $67(12.1)$ \\
\hline Diarrhea & $81(14.6)$ \\
\hline Anosmia & $29(5.2)$ \\
\hline Ageusia/Dysgeusia & $51(9.2)$ \\
\hline Syncope & $6(1.1)$ \\
\hline Respiratory rate, breaths/min & $20 \pm 5$ \\
\hline Heart rate, beats/min & $90 \pm 16$ \\
\hline Arterial pressure, systolic - diastolic, $\mathrm{mmHg}$ & $127 \pm 22-75 \pm 13$ \\
\hline Body temperature, ${ }^{\circ} \mathrm{C}$ & $37.1 \pm 0.8$ \\
\hline $\mathrm{SpO}_{2}, \%$ & $96.2 \pm 3.7$ \\
\hline \multicolumn{2}{|l|}{ Laboratory tests } \\
\hline White blood count-n/mmc & $7788 \pm 5421$ \\
\hline Neutrophils—n/mmc & $6091 \pm 6547$ \\
\hline Lymphocytes-n/mmc & $1673 \pm 2906$ \\
\hline Eosinophils—n/mmc & $0.541 \pm 0.1332$ \\
\hline Platelets-n/mmc & $221 \pm 90$ \\
\hline aPTT & $1.80 \pm 13$ \\
\hline INR & $1.2 \pm 0.6$ \\
\hline Creatinine $-\mathrm{mg} / \mathrm{dl}$ & $1.07 \pm 0.99$ \\
\hline Urea-mg/dl & $44.2 \pm 36.5$ \\
\hline Sodium-mmol/L & $138 \pm 4.7$ \\
\hline Potassium—mmol/L & $4.1 \pm 0.5$ \\
\hline Lactate dehydrogenase-U/L & $288 \pm 185$ \\
\hline
\end{tabular}


Table 1 (continued)

\begin{tabular}{ll}
\hline $\mathrm{C}-$ Reactive protein-mg/dl & $6.2 \pm 7.2$ \\
Procalcitonin-ng/ml & $1.7 \pm 12$ \\
Arterial blood gas & \\
$\mathrm{pH}$ & $7.42 \pm 0.53$ \\
$\mathrm{PaO}_{2}-\mathrm{mmHg}$ & $75 \pm 20.1$ \\
$\mathrm{PaCO}_{2}-\mathrm{mmHg}$ & $33.7 \pm 6.6$ \\
$\mathrm{SatO}_{2}$ & $96 \pm 4.5$ \\
$\mathrm{P} / \mathrm{F}$ & $349.7 \pm 97.2$ \\
$\mathrm{HCO}_{3}-\mathrm{mmHg}$ & $23.8 \pm 3.3$ \\
$\mathrm{Blood} \mathrm{lactate}-\mathrm{mmol} / \mathrm{L}$ & $1.2 \pm 1$ \\
\hline
\end{tabular}

Data are presented as numbers $(n)$ and percentages $(\%)$ for dichotomous values, and average and standard deviation for the continuous values. $R A A S$ renin-angiotensin-aldosterone system, $A R B S$ angiotensin-receptor blockers, COPD chronic obstructive pulmonary disease, $T I A$ transient ischemic attack, $p T T$ partial thromboplastin time, INR international normalized ratio

dehydrogenase ( $288 \mathrm{U} / \mathrm{L} \pm 185)$. In the majority of cases, arterial blood gas analysis showed a normal $\mathrm{pH}$ and hypocapnia (Table 1).

Viral pneumonia was confirmed using imaging in 485 patients $(87.5 \%)$. The ROX index in the overall population was $24.3 \pm 6.5$.

The baseline characteristics of the discharged and hospitalized patients are listed in Table 2 .

The percentage of patients hospitalized was $69.3 \%$ $(N=384)$; they tended to be older and had more comorbidities than the other group. The analysis in the present study showed that a ROX index value $<25.7$ was reliable in predicting the need for hospitalization with a sensitivity of $76.5 \%$ and a specificity of $65.6 \%$ (AUC $=0.737$, $95 \%$ CI $0.696-0.779, p<0.001)$. In particular, when the population was divided based on age, the ROX index value was an average of 26 for patients $<65$ years old (sensitivity $71 \%$, specificity $60 \%, \mathrm{AUC}=0.667,95 \% \mathrm{CI}$ $0.607-0.728, p<0.001$ ) and 23.3 for patients $\geq 65$ years old (sensitivity $81 \%$, specificity $62.4 \%$, AUC $=0.764,95 \%$ CI $0.686-0.842, p<0.001)$. The ROC curve is shown in Fig. 1a.

The accuracy of NEWS2 and RR in the prediction of hospitalization were also calculated and were lower than the ROX index. The NEWS2 sensitivity was $66 \%$ and the specificity was $69 \%$ (area under the receiver operating characteristic curve [AUROC] 0.736 ; 95\% CI 0.688-0.805) whereas the RR sensitivity was $71 \%$ and the specificity $56 \%$ (AUROC 0.692; 95\% CI 0.649-0.734).

After conducting a 30-day follow-up, 82 (14.8\%) patients, having a mean age of $82.1 \pm 9(56-100)$, died after $10.35 \pm 7.21$ days; 79 patients were $\geq 65$ years and 51 were male $(62.2 \%)$. A ROX index $<22.3$ was statistically related to higher 30 -day mortality, with a sensitivity of $74.8 \%$ and a specificity of $65.9 \%(\mathrm{AUC}=0.764,95 \%$ CI $0.708-0.820$, $p<0.001$ ) (Fig. 1b).

Moreover, data showed that a ROX index value $<26$ was able to identify patients with viral pneumonia, as assessed at CT scan (sensitivity $62.3 \%$, specificity $60 \%, \mathrm{AUC}=0.657$, $95 \%$ CI $0.595-0.719, p<0.001)$. Table 3 shows the ROC analysis of the ROX index.

During hospitalization, 24 patients $(6.25 \%)$, having a mean age of 68.7 (56-79), underwent endotracheal intubation: $58.3 \%$ were male. The mean ROX index just before intubation was 3.8 (range 2.5-5.71). At the 30-day followup, 16 of them $(66.7 \%)$ were alive.

Of the 554 patients, 8 patients were discharged but returned to the ED within the subsequent 7 days and were hospitalized. The mean ROX indices varied as follows: 30.3 (6.2; range 21.9-39.4) at the first assessment and 24.6 (5.5; $14.5-29.5)$ at the second assessment, $p=0.012$.

\section{Discussion}

This monocentric study suggested adding the ROX index to the first ED evaluation of COVID-19 patients to identify the cut-off values able to correlate with viral pneumonia on imaging tests (CT or ultrasound). This ability is particularly important when the pandemic impacts the limited ED resources when patients suitable for undergoing imaging tests have to be safely selected. In the present cohort, a ROX index value $<26$ was associated with imaging findings of viral pneumonia.

Furthermore, it was demonstrated that the ROX index was also an effective tool for differentiating, at admission to the ED, patients with a COVID-19 infection requiring hospital admission (ROX index <25.7) from those who could be safely discharged. For patients $\geq 65$ years old, the cut-off value of the ROX index was 23.3.

The decision regarding hospitalization in the present cohort of patients was made based on the usual decisionmaking process used in the acute ED patient (i.e. based on multimodal elements: laboratory and imaging data, respiratory pattern, blood gas analytical data, comorbidity data and patient characteristics). The ROX index cut-off was then extrapolated to the group of hospitalized patients, keeping in mind that it could not be the only element to be used, but had to be included in a broader spectrum of tests.

In addition, a ROX index of $<22.3$, related to the 30-day mortality rate, was lower than its values for hospitalization and pneumonia findings, confirming that a lower ROX index predicted a higher mortality risk. It is interesting to note that only 8 of the 170 patients discharged returned to the ED and were consequently hospitalized. In this small subset of patients, the reduction in the ROX index was an indicator of worsening. 
Table 2 Baseline characteristics of the cohort comparing discharged and hospitalized patients

\begin{tabular}{|c|c|c|c|}
\hline & Discharged $(n=170)$ & $\begin{array}{l}\text { Hospitalized or death } \\
(n=384)\end{array}$ & $P$ value \\
\hline Age, years & $46.7 \pm 14.8$ & $68 \pm 17$ & $<0.001$ \\
\hline Gender, $n(\%)$ & & & 0.001 \\
\hline Male & $72(42.4)$ & $224(58.3)$ & \\
\hline Female & $98(57.6)$ & $160(41.7)$ & \\
\hline \multicolumn{4}{|l|}{ Comorbidities, $n(\%)$} \\
\hline Hypertension & $23(13.5)$ & $181(47.1)$ & $<0.001$ \\
\hline Use of RAAS inhibitors & $5(2.9)$ & $47(12.2)$ & $<0.001$ \\
\hline Use of ARB inhibitors & $9(5.3)$ & $46(12)$ & 0.014 \\
\hline Diabetes mellitus & $8(4.7)$ & $54(14.1)$ & 0.001 \\
\hline COPD & $3(1.8)$ & $55(14.3)$ & $<0.001$ \\
\hline Asthma & $6(3.5)$ & $7(1.8)$ & NS \\
\hline Other respiratory diseases & $3(1.8)$ & $19(5)$ & NS \\
\hline Ischemic heart disease & $2(1.2)$ & $39(10.2)$ & $<0.001$ \\
\hline Active cancer & $5(2.9)$ & $28(7.3)$ & NS \\
\hline Chronic kidney disease & $1(0.6)$ & $45(11.7)$ & $<0.001$ \\
\hline Previous TIA/stroke & $4(2.4)$ & $22(5.7)$ & NS \\
\hline Liver disease & $3(1.8)$ & $19(5)$ & NS \\
\hline Cognitive impairment & $0(0)$ & $72(18.8)$ & $<0.001$ \\
\hline Onset of symptoms, days & $7.2 \pm 6.3$ & $5.9 \pm 4.6$ & NS \\
\hline \multicolumn{4}{|c|}{ Clinical features at ED admission, $n(\%)$} \\
\hline Fever & $133(78.2)$ & $328(85.4)$ & 0.036 \\
\hline Dyspnea & $53(31.2)$ & $156(40.6)$ & 0.037 \\
\hline Cough & $109(64.1)$ & $206(53.6)$ & 0.026 \\
\hline Conjunctivitis & $6(3.5)$ & $2(0.5)$ & 0.012 \\
\hline Rhinorrhea & $12(7.1)$ & $9(2.3)$ & 0.014 \\
\hline Sore throat & $26(15.3)$ & $13(3.4)$ & $<0.001$ \\
\hline Headache & $31(18.2)$ & $14(3.7)$ & $<0.001$ \\
\hline Asthenia & $33(19.4)$ & $57(14.8)$ & NS \\
\hline Myalgia/Arthralgia & $37(21.8)$ & $30(7.8)$ & $<0.001$ \\
\hline Diarrhea & $32(18.8)$ & $49(12.8)$ & NS \\
\hline Anosmia & $21(12.4)$ & $8(2.1)$ & $<0.001$ \\
\hline Ageusia/Dysgeusia & $32(18.8)$ & $19(5)$ & $<0.001$ \\
\hline Syncope & $1(0.6)$ & $5(1.3)$ & NS \\
\hline Respiratory rate, breaths/min & $17 \pm 3$ & $21 \pm 6$ & $<0.001$ \\
\hline Heart rate, beats/min & $88 \pm 15$ & $91 \pm 17$ & NS \\
\hline $\begin{array}{l}\text { Arterial pressure, systolic - dias- } \\
\text { tolic, } \mathrm{mmHg}\end{array}$ & $133 \pm 20-78 \pm 11$ & $125 \pm 22-74 \pm 13$ & 0.001 \\
\hline Body temperature, ${ }^{\circ} \mathrm{C}$ & $36.8 \pm 0.6$ & $37.3 \pm 0.9$ & $<0.001$ \\
\hline $\mathrm{SpO}_{2}, \%$ & $97.8 \pm 1.6$ & $94.7 \pm 4.3$ & $<0.001$ \\
\hline
\end{tabular}

Data are presented as number $(n)$ and percentage (\%) for the dichotomous values, and average and standard deviation for the continuous values. RAAS renin-angiotensin-aldosterone system, ARBs angiotensin-receptor blockers, COPD chronic obstructive pulmonary disease, TIA transient ischemic attack, NS not significant
The ROX index is an easy-to-use tool which relies on variables directly linked to oxygenation (assessed by $\mathrm{SpO}_{2} /$ $\mathrm{FiO}_{2}$ ) and respiratory distress (assessed by RR), potentially leading to pump ineffectiveness. Due to the relationship between these variables, they can compound one another since severe patients are more likely to have a lower $\mathrm{SpO}_{2} /$
$\mathrm{FiO}_{2}$ and a higher RR [10]. The variables required are noninvasive and are easily and quickly obtained, as well as being reproducible. The present study demonstrated the higher accuracy of the ROX index as compared to RR alone in the prediction of hospitalization. Moreover, the accuracy of the ROX index which was comparable to NEWS2, a well-known 


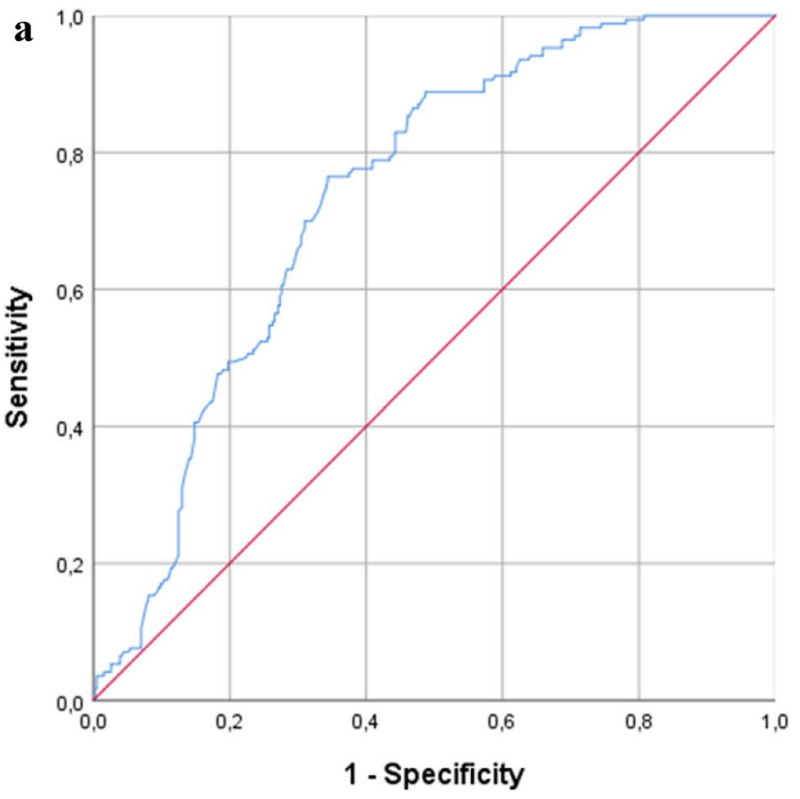

Fig. 1 a Receiver operating characteristic (ROC) analysis of the ROX index in predicting hospitalization (AUC 0.737; 95\% CI, 0.696 $0.779 ; p<0.001)$. b Receiver operating characteristic (ROC) analysis

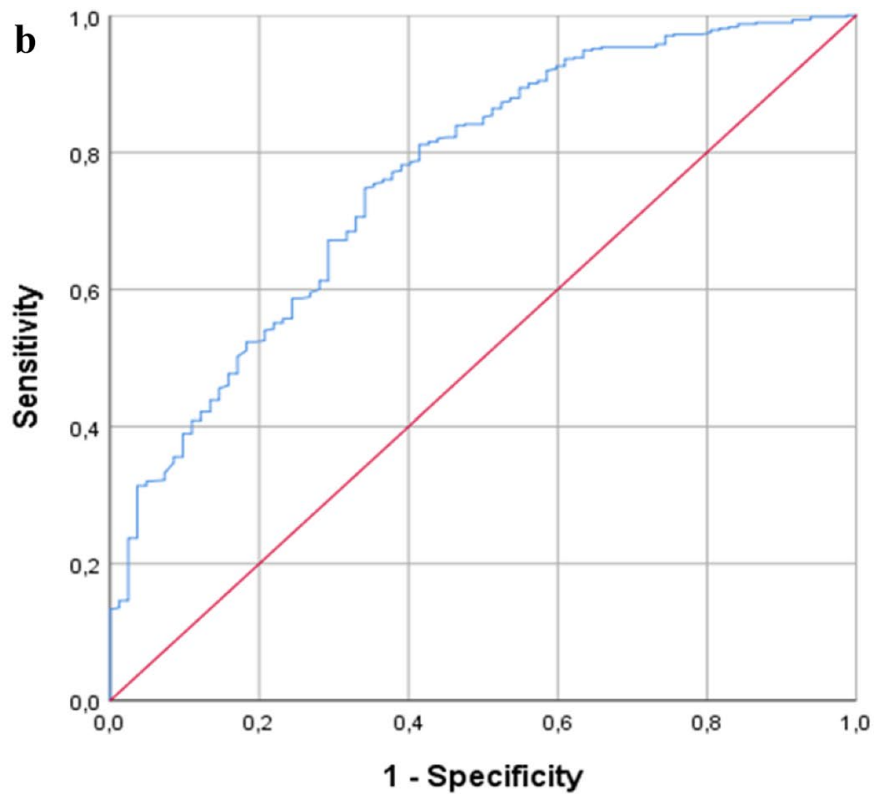

of the ROX index in predicting 30-day mortality (AUC 0.764; $95 \%$ CI, 0.708-0.820; $p<0.001$ )
Table 3 AUROC, 95\% CI, $P$ Value, Sensitivity and Specificity derived from the ROC analysis of the ROX index

\begin{tabular}{lllllll}
\hline Variable & ROX index & AUROC & $95 \%$ CI & $p$ value & Sensitivity (\%) & Specificity (\%) \\
\hline Hospitalization & 25.7 & 0.737 & $0.696-0.779$ & $<0.00176 .5$ & 65.6 \\
Patients $<65$ years old & 26 & 0.667 & $0.607-0.728$ & $<0.00171$ & 60 \\
Patients <65 years old & 23.3 & 0.764 & $0.686-0.842$ & $<0.00181$ & 62.4 \\
30 day mortality & 22.3 & 0.764 & $0.708-0.820$ & $<0.00174 .8$ & 65.9 \\
Viral pneumonia & 26 & 0.657 & $0.595-0.719$ & $<0.00162 .3$ & 60 \\
\hline
\end{tabular}

$A U R O C$ area under the receiver operating characteristic curve score for the assessment of the severity of illness in the ED which utilizes more variables and time required to be calculated was pointed out.

During the COVID-19 pandemic, the main challenge has been the evaluation of an elevated number of patients suffering from a novel disease, frequently requiring hospitalization, without a proportional increase in resources and hospital capacity [9].

This study suggested the application of the ROX index during the first assessment of COVID-19 patients in the ED, as an additional tool for helping the emergency physician evaluate the clinical severity of patients to safely discharge patients from the hospital. The present data confirmed that the ROX index, together with laboratory, imaging and clinical findings, could be a reliable and useful tool in the emergency setting.

To the best of the Authors' knowledge, this is the first study with a large population in which the ROX index was used in patients with SARS-CoV-2 infection at admission in the ED. Moreover, the majority of the present population did not receive respiratory support and did not fulfill ARDS criteria [16]. This explained why the present ROX index values were different from those which Roca et al. [10] defined in the original study.

On the other hand, the main limitations of this study were its monocentric design and the nature of the pandemic crisis. Furthermore, the present data showed that this was a "mild" population; it would be appropriate to evaluate whether the same results could be extended to a patient population with more severe clinical features. In fact, the "true" $\mathrm{FiO}_{2}$ delivered to patients was not measured and it could not be excluded that air entrainment occurred, especially in patients with high respiratory demand. This should also be considered a preliminary study due to the fact that these data were collected during the first wave of COVID-19 in which knowledge of the disease and its treatment were continually being updated. Additional studies are necessary to validate the use of the ROX index, its cut-off values and 
its feasibility in the evolving context of the disease, possibly with a multicentric design.

Considering what was previously mentioned, the ROX index seems to be a good combination of accuracy, noninvasivity and promptness, especially in those scenarios in which a blood gas analyzer is not available. For instance, it could be used by the triage nurse to place patients at adequate priority levels, by attributing color codes which are directly related to waiting time in the ED. For the same reasons, the Authors also suggest using the ROX index for patients having suspicious COVID-19 symptoms prior to admission to the ED, such as e,g., using pulse oximetry in the territorial health care services. The expectation is to help general practitioners to better manage outpatients by means of a common index, especially in the unfortunate hypothesis of another wave of COVID-19.

Author contributions Alice Gianstefani and Gabriele Farina designed the study, reviewed and edited the manuscript; Francesca Alvau, Maria Laura Artesiani, Sara Bonfatti, Francesca Campinoti, Ilaria Caramella, Michele Ciordinik, Andrea Lorusso, Sara Nanni and Daniela Nizza enrolled the patients, reviewed the literature, wrote the manuscript and produced the figures. Veronica Salvatore made a substantial contribution to the statistical analysis. Stefano Nava and Fabrizio Giostra reviewed and edited the manuscript. All authors read and approved the final manuscript in compliance with Ethical Standards.

Funding This study did not receive any specific grant from funding agencies in the public, commercial or not-for-profit sectors.

\section{Declarations}

Conflict of interest The authors declare that they have no conflict of interest.

Ethical approval Approval was obtained from the Ethics Committee of the University of Bologna (Ethics approval number: 551/2020/Oss/ AOUBo). The procedures used in this study adhered to the tenets of the Declaration of Helsinki.

Human and animal rights statement Human rights have been respected. Animal rights not applicable.

Informed consent Verbal informed consent of patients was regularly obtained as indicated by Ethics Committee.

\section{References}

1. Riccardo F, Andrianou X, Bella A (2020) Epidemia COVID-19. Roma 2020

2. Diagnostic testing for SARS-CoV-2: interim guidance. World Health Organization 11 September 2020

3. Kucirka LM, Lauer SA, Laeyendecker O, Boon D, Lessler J (2020) Variation in false-negative rate of reverse transcriptase polymerase chain reaction-based SARS-CoV-2 tests by time since exposure. Ann Intern Med 173(4):262-267. https://doi. org/10.7326/M20-1495
4. Peyrony O, Marbeuf-Gueye C, Truong V, Giroud M, Rivière C, Khenissi K, Legay L, Simonetta M, Elezi A, Principe A, Taboulet P, Ogereau C, Tourdjman M, Ellouze S, Fonatine JP (2020) Accuracy of emergency department clinical findings for diagnosis of coronavirus disease 2019. Ann Emerg Med 76(4):405-412. https ://doi.org/10.1016/j.annemergmed.2020.05.022

5. Chen N, Zhou M, Dong X, Qu J, Gong F, Han Y, Qiu Y, Wang J, Liu Y, Wei Y, Xia J, Yu T, Zhang X, Zhang L (2020) Epidemiological and clinical characteristics of 99 cases of 2019 novel coronavirus pneumonia in Wuhan, China: a descriptive study. Lancet 395(10223):507-513. https://doi.org/10.1016/S0140 $-6736(20) 30211-7$

6. Pascarella G, Strumia A, Piliego C, Bruno F, Del Buono R, Costa F, Scarlata S, Agrò FE (2020) COVID-19 diagnosis and management: a comprehensive review. J Intern Med 288(2):192-206. https://doi.org/10.1111/joim.13091

7. Wu Z, McGoogan JM (2020) Characteristics of and important lessons from the coronavirus disease 2019 (COVID-19) outbreak in China: summary of a report of 72314 cases from the Chinese center for disease control and prevention. JAMA 323(13):12391242. https://doi.org/10.1001/jama.2020.2648

8. Gattinoni L, Chiumello D, Rossi S (2020) COVID-19 pneumonia: ARDS or not? Crit Care 24(1):1-3

9. Fagiuoli S, Lorini FL, Remuzzi G (2020) Covid-19 Bergamo Hospital Crisis Unit. Adaptations and Lessons in the Province of Bergamo. N Engl J Med 382(21):71. https://doi.org/10.1056/ NEJMc2011599.

10. Roca O, Messika J, Caralt B, García-de-Acilu M, Sztrymf B, Ricard JD, Masclans JR (2016) Predicting success of high-flow nasal cannula in pneumonia patients with hypoxemic respiratory failure: The utility of the ROX index. J Crit Care 35:200-205. https://doi.org/10.1016/j.jcrc.2016.05.022

11. Roca O, Caralt B, Messika J, Samper M, Sztrymf B, Hernández G, García-de-Acilu M, Frat JP, Masclans JR, Ricard JD (2019) An index combining respiratory rate and oxygenation to predict outcome of nasal high-flow Therapy. Am J Respir Crit Care Med 199(11):1368-1376. https://doi.org/10.1164/rccm.201803-0589OC

12. Frat JP, Thille AW, Mercat A, Girault C, Ragot S, Perbet $S$ et al (2015) High-flow oxygen through nasal cannula in acute hypoxemic respiratory failure. N Engl J Med 372(23):2185-2196. https ://doi.org/10.1056/NEJMoa1503326

13. Rodriguez M, Thille AW, Boissier F, Veinstein A, Chatellier D, Robert R, Le Pape S, Frat JP, Coudroy R (2019) Predictors of successful separation from high-flow nasal oxygen therapy in patients with acute respiratory failure: a retrospective monocenter study. Ann Intensive Care 9(1):101. https://doi.org/10.1186/s1361 3-019-0578-8

14. Mauri T, Carlesso E, Spinelli E, Turrini C, Corte FD, Russo R, Ricard JD, Pesenti A, Roca O, Grasselli G (2019) Increasing support by nasal high flow acutely modifies the ROX index in hypoxemic patients: A physiologic study. J Crit Care 53:183-185. https ://doi.org/10.1016/j.jcrc.2019.06.020

15. Royal College of Physicians. National Early Warning Score (NEWS) 2: Standardising the assessment of acute-illness severity in the NHS. Updated report of a working party. London: RCP, December 2017

16. ARDS Definition Task Force, Ranieri VM, Rubenfeld GD, Thompson BT, Ferguson ND, Caldwell E, Fan E, Camporota L, Slutsky AS (2012) Acute respiratory distress syndrome: the Berlin Definition. JAMA 307(23):2526-33. https://doi.org/10.1001/ jama.2012.5669

Publisher's Note Springer Nature remains neutral with regard to jurisdictional claims in published maps and institutional affiliations. 